\title{
What Isn't Guidance?
}

\author{
GEORGE E. MYERS
}

Professor Emeritus of Education, University of Michigan

$\mathrm{T}$ HE U. S. OFFICR OF EDUCATION served well the cause of guidance through its publication entitled, Offerings in Guidance Work in Colleges and Universities, Summer, 1949. Intended to aid those interested in guidance work in selecting the higher educational institution to attend during the summer, the bulletin has other important values also.

In the first place, this publication focuses attention on the remarkable growth in the number of colleges and universities that offer courses labeled guidance. When the writer first offered a course in vocational guidance at the University of Michigan 30 years ago, only a few other universities had announced similar offerings. Even eight years ago, the number of institutions that provided any special preparation for guidance workers was only 52, according to Brewer's History of $V_{0}$ cational Guidance. Now nearly 300 higher educational institutions, well distributed through the 48 states, the District of Columbia, Hawaii, and Puerto Rico, provide such courses.

In the second place, the bulletin shows that a wide range of specialized courses in guidance is now available. True, most of the nearly 300 institutions wisely attempt to provide only one or two basic courses that deal with the principles and techniques of guidance. On the other hand, a considerable number of well-known universities offer a long list of courses ranging from those of an introductory nature to practicums, workshops, and seminars. Included in the list are such titles as: "Organization and Administration of Guidance," "School Counseling Procedures," "Tests and Inventories in Counseling and Guidance," "Interviewing and Counseling," "Vocational Guidance and Occupational Information," "Occupational Surveys," "Non-directive Counseling," "Community Resources for Guidance," "Sources of Occupational Information," and many others.

Progress has been rapid in recent years toward comprehensive preparation for specialized guidance work.

In the third place-and this is the principal reason for the article you are now readingthe publication shows an astounding lack of discrimination regarding what are and what are not "Offerings in Guidance Work." In requesting the desired information from educational institutions, the U. S. Office of Education was quite explicit. "For the purposes of this survey," the directions read, "consider as guidance courses only those dealing with preparation for guidance duties, such as courses in counseling techniques, analysis of the individual, principles and practices of guidance, or occupational information. Do not include general education and psychology courses, such as statistics, abnormal psychology, educational administration, or secondary education." Notwithstanding these explicit instructions (which should have been unnecessary), the publication contains a great variety of course titles not only in general education and psychology but also in speech, mental hygiene, psychiatry, sociology, economics, political science, and business administration.

Here are some of the course titles: "Fundamentals of School Administration," "Supervision of Instruction," "School Finance and Business Administration," "Problems of Teaching Personnel," "Projective Methodo- 
logy," "Measurement and Evaluation of Learning," "Educational Statistics," "The School and Community," "Education for Family Life," "Consumer Education," "Vocational Education," "Recent Trends in Educational Measurement," "Curriculums for Mentally Retarded," "Speech Disabilities," "Clinical Practice in Speech Therapy," "Seminar in Speech Pathology," "The Improvement of Reading," "Educational Psychology," "Social Psychology," "Abnormal Psychology," "Child Psychology," "Psychology of Adolescence," "Clinical Psychology," "Industrial Psychology," "Psychology of Reading," "Psychology of the Exceptional Child," "Growth and Development of Children," "Psychology of Behavior," "Individual Differences," "Dynamics of Behavior," "Collective Behavior," "Interpretation of Early Childhood Behavior," "The Deviant Individual," "Mental Hygiene," "Psychiatric Problems in Education," "Introduction to the Field of Social Work," "Social Institutions," "The Family," "Parent-Child Relationships," "Child Welfare,"
"Socialization of the Child," "Delinquent Children," "Criminology," "Labor Problems and Trade Unionism," "Labor and Social Movements," "Labor Legislation and Social Insurance," "Evolution of Industrial Society," "Job Evaluation and Merit Rating," "The Labor Market," "Introduction to Public Administration," "Government Problems of Democracy"!!

Is it too much to hope that those responsible for guidance courses in colleges and universities will be more discriminating when they supply information for the next annual publication of this nature? Is it too much to expect that the U.S. Office of Education will edit more carefully in the future the material that it publishes under the title: Offerings in Guidance in Colleges and Universities?

Only a few years ago the question was, "What is guidance?" Must this now be changed to, "What isn't guidance?" Has another once valuable educational term lost its meaning because it is used to cover so many different things?

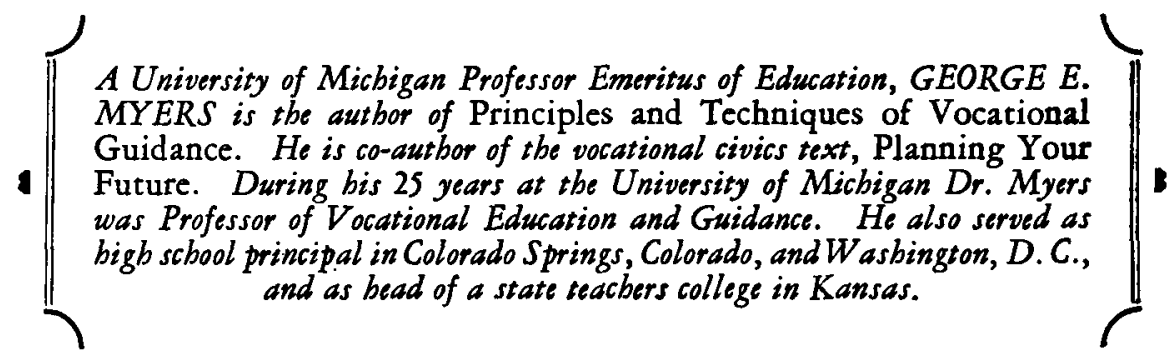

